\title{
Discrimination avoidance learning with alternate discontinuous and continuous US escape trials'
}

JAMES N. SHAFER and JOHN H. HESS, West Virginia University, Morgantown, W. Va. 26506

It has been suggested that the avoidance performance of animals trained under a combined discontinuous/continuous shock procedure would be superior to that of animals trained under standard discontinuous shock procedure. The present study indicates that animals receiving, alternately, continuous or discontinuous shock on escape trials, exhibit shorter escape response latencies and better avoidance acquisition than animals trained under standard discontinuous shock for all escape trials. Under the combined discontinuous/continuous shock procedure, avoidance responses occur earlier and more frequently in escape-avoidance training as escape responses to the US become more efficient in topography and shorter in latency.

It has been hypothesized that discriminated avoidance is effectively produced in the bar-press situation by discontinuous shock because this procedure increases generalization of escape responses to the preshock period (D'Amato, Keller, \& DiCara, 1964). A test of the generalization hypothesis (Hess \& Shafer, 1968a) indicated that the occurrence of the escape response in the absence of shock is not a crucial variable accounting for the superior avoidance learning obtained with discontinuous shock procedures.

In an examination of the escape response distribution within the discontinuous US on- and off-shock periods, Hess \& Shafer (1968b) found that Ss make a disproportionate number of responses during the on-shock period. For individual Ss the number of escape responses initiated to on-shock periods was significantly correlated with avoidance performance. It was suggested that the use of a discontinuous US provides a systematic shaping procedure in which the short on-shock periods have the dual effect of breaking up freezing behaviors and simultaneously reinforcing S's successive movements toward completion of the lever-press response.

The correlation of avoidance performance with escape responses executed during on-shock periods reveals the importance of US termination in the acquisition of avoidance responding. The use of a discontinuous shock US is effective in conditioning a lever-press avoidance response insofar as freezing behavior is reduced and the lever-press is shaped but is ineffective insofar as many escape responses are made during off-shock periods. It was hypothesized (Hess \& Shafer, 1968b) that the avoidance performance of a group of animals trained under a combined continuous/discontinuous shock procedure would be significantly better than that of animals trained under standard discontinuous shock procedure. The present experiment compares avoidance performance under the two conditions.

\section{METHOD}

The Ss were 10 male Sprague-Dawley rats, 80 to 100 days old, selected from a colony maintained by the Department of Psychology at West Virginia University. Ss were conditioned in a Scientific Prototype operant chamber with a 4000 -cps tone $\mathrm{CS}$ at $50 \mathrm{~dB}$ and a $.3-\mathrm{mA}$ scrambled US. The ITI averaged $35 \mathrm{sec}$ while the CS-US interval was $5 \mathrm{sec}$.

Subjects were randomly assigned to either a control group receiving standard discontinuous shock on escape trials or to an experimental group receiving, alternately, discontinuous or continuous shock. After the escape response had been shaped to a criterion of five self-initiated escapes from continuous

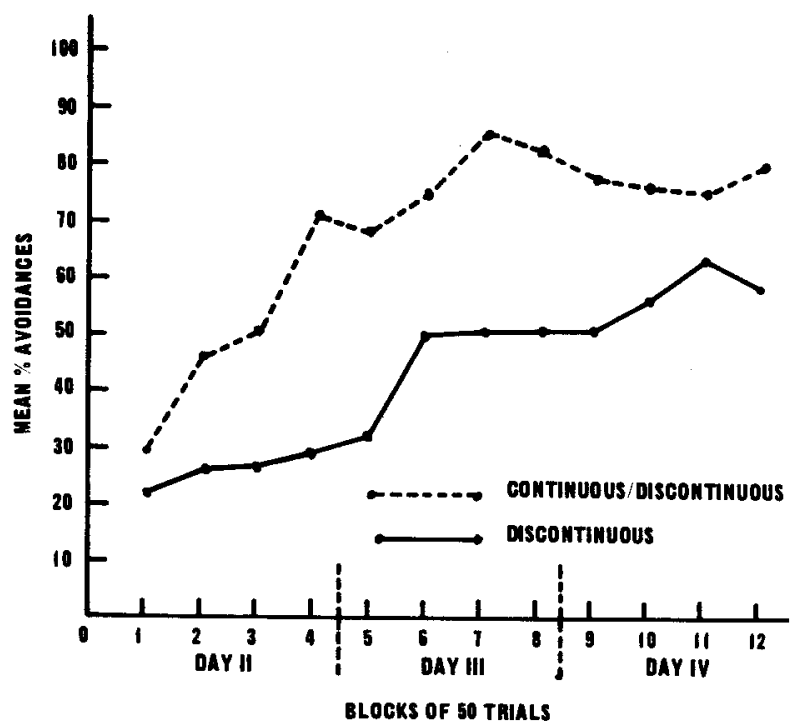

Fig. 1. Avoidance learning as a function of type of US.

shock, Ss received 50 trials of pretraining under their respective experimental conditions on Day 1 . Ss then received 200 escape-avoidance trials on each of Days 2, 3, and 4. Avoidances, escapes, and number of shocks per escape trial (on discontinuous shock trials) were recorded for each block of 50 trials.

\section{RESULTS AND DISCUSSION}

A Lindquist I analysis was performed on both the avoidance data and on the mean number of shocks received on escape trials (during the discontinuous shock condition). Ss trained under combined continuous/discontinuous shock were found to have significantly better avoidance performance $(F=7.44$, $\mathrm{df}=1 / 8, \quad \mathrm{p}<.05)$ than $\mathrm{Ss}$ trained only with standard discontinuous shock procedure. Mean percentages of avoid-

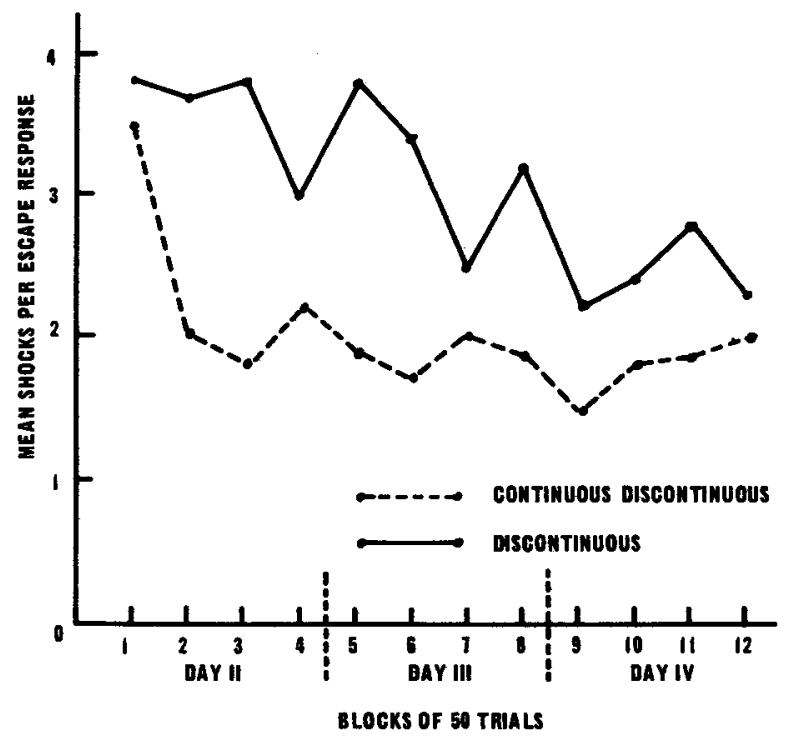

Fig. 2. Mean shocks per escape response as a function of type of US. 
ance responses in 50-trial blocks are presented for both groups in Fig. 1.

Subjects in the experimental group received significantly fewer shocks per escape trial $(F=7.34$, $\mathrm{df}=1 / 8, \mathrm{p}<.05)$ than did those in the control group. Fig. 2 shows the mean number of shocks received per discontinuous US escape trial in 50-trial blocks for both groups. Mean number of shocks per escape response may be considered a measure approximating escape response latency to discontinuous shock.

Avoidance performance is clearly unrelated to S's opportunity to execute escape responses in off-shock periods but appears to be related to escape response latency. Our analysis of the conditions producing the superior avoidance performance exhibited by Ss in the experimental group in this study is as follows: Presentation of discontinuous shock for half the escape trials served to eliminate freezing behaviors incompatible with efficient escape responding. Presentation of continuous shock on half the escape trials (a) served to shorten the latency of escape responses, and (b) provided a more favorable reinforcement contingency in which the US was terminated by the escape response.

\section{REFERENCES}

D'AMATO, M. R., KELLER, D., \& DiCARA, L. Facilitation of discriminated avoidance learning by discontinuous shock. Journal of Comparative \& Physiological Psychology, 1964, 58, 344-349.

HESS, J. H., \& SHAFER, J. N. Discontinuous shock and generalization to the preshock period in discriminated avoidance learning. Psychonomic Science, 1968, 10, 175-176.

HESS, J. H., \& SHAFER, J. N. Escape response distribution and discriminated avoidance of discontinuous shock. Psychonomic Science, 1968, 11, 255-256.

\section{NOTE}

1. Supported in part by United States Public Health Service Grant MH $11634-02$.

(Continued from page 236)

Relative to the baseline condition, a marked increase in the frequency of aggressive behavior occurred during the FR-20 reinforcement schedule sessions. The attacks that occurred in these sessions were not associated with any particular segment of the FR response sequence, such as the postreinforcement pause (Gentry, 1968; Hutchinson et al, 1968).

Relative to the FR-20 condition, an obvious decrease in aggressive behavior occurred during the FR-40 and FR-60 conditions. Under the FR-40 and FR-60 conditions, the experimental Ss spent more time pressing the response lever for reinforcement and less time in aggressive, exploratory, grooming, and general body contact behaviors than they had in the FR-20 condition. As is obvious from Fig. 1, there was little difference in the incidence of attack for the FR-40 and FR-60 conditions. As was the case in the FR-20 condition, aggressive responses under FR-40 and FR-60 were unrelated to any specific segment of the FR response sequence.

The changes in aggressive behavior across the various phases of the experiment were evaluated by a Treatment by Ss repeated-measures analysis of variance. The main effect of the FR schedule requirement was significant at the .01 level $(F=6.53, \mathrm{df}=3 / 73)$. $T$ tests indicated that the incidence of attack was greater for the FR-20 condition than for all other conditions $(t=2.45$, $\mathrm{df}=73, \mathrm{p}<.05)$. No significant differences were obtained, however, between the baseline, FR-40, and FR-60 conditions $(p>.10)$.

\section{DISCUSSION}

The results of the present study apparently confirm the generality of the FR schedule-induced aggression data obtained by Gentry (1968) and Hutchinson et al (1968). Relative to the baseline period, the increase in aggression under the FR-20 condition in the present study indicates that rats exposed to an FR schedule of water reinforcement show the same general increase in attack behavior that has been observed in pigeons and primates that earn food reinforcement under FR instrumental response requirements. The present results differ from previous reports on schedule-induced aggression, however, both with respect to the relationship between attack frequency and the magnitude of the FR requirement, and with respect to the primary location of attack behavior in the FR response sequence. With regard to the first issue, Hutchinson et al (1968) found that the frequency of an aggressive biting response in primates increased as the FR requirement increased. By comparison, the present results suggest that aggression shows an initial increase, then a marked decrease as the $F R$ requirement for water reinforcement is progressively raised to higher values. With regard to the second issue, both Gentry (1968) and Hutchinson et al (1968) reported that the greatest incidence of aggressive behavior occurs during the postreinforcement pause and during the early segments of the FR response run. The present data, however, suggest that the attack response, when it does occur, is equally probable at any temporal point in the interreinforcement interval. Additional research in this area would seem to be warranted to determine whether the present results are primarily attributable to species differences in aggressive behavior, or associated with differential effects of differing reinforcers (e.g., food vs water) on aggressive behavior.

\section{REFERENCES}

AZRIN, N. H., HUTCHINSON, R. R., \& HAKE, D. F. Extinctioninduced aggression. Journal of the Experimental Analysis of Behavior, 1966, 9, 191-204.

GENTRY, W. D. Fixed-ratio schedule-induced aggression. Journal of the Experimental Analysis of Behavior, 1968, 11, 813-817.

HUTCHINSON, R. R., AZRIN, N. H., \& HUNT, G. M. Attack produced by intermittent reinforcement on a concurrent operant response. Journal of the Experimental Analysis of Behavior, 1968, 11, 489-495.

ULRICH, R. E., \& AZRIN, N. H. Reflexive fighting in response to aversive stimulation. Journal of the Experimental Analysis of Behavior, 1962, 5, 511-520.

\section{NOTE}

1. This research was supported in part by Grants MH-08775 and MH-12025 from the National Institutes of Health, Robert W. Schaeffer, principal investigator. 